\title{
Gender, samenleving en stedelijk ontwerp
}

AUTEUR Mukarram Abbas

FOTOGRAFIE Ernst Grantham-Hill, David Goehring, Yvonne Rijpers

VERTALERS Bas van Leeuwen, Yvonne Rijpers

De relatie tussen gender en stedelijk ontwerp roept een hoop gedachten bij me op. Is het waar? Ervaren vrouwen de stad echt op een andere manier dan mannen? Als je dit gelooft, zie je het hele proces omtrent stedenbouwkunde en ontwerp in een ander perspectief.

Er wordt vaak gedacht dat de term gender en het bijbehorende discours alleen over vrouwen en feministische issues gaat. Dit is niet het geval. Gender speelt een belangrijke rol in het debat over zowel vrouwen als mannen en de relatie van beide geslachten tot elkaar. Gender gaat onder andere over de rollen, de verantwoordelijkheden, de behoeften en de interesses van beide geslachten. Toch gaat het merendeel van de gender discussies in het specifiek over vrouwen issues door het onderzoek naar door de geldigheid van vrouwenrechten in verschillende aspecten van de samenleving. Voorbeelden hiervan zijn de thema's vrouwen en armoede, vrouwen en gezondheid en vrouwen en onderwijs.

De betekenis van de term gender staat ter discussie sinds Gayle Rubin haar concept van het sekse/gender systeem presenteerde. Vanaf dat moment is gender op vele manieren door vele academici vanuit verschillende perspectieven gedefinieerd. Matrix (1984) en Moser (1993) zien gender als het verschil tussen man en vrouw binnen hetzelfde huishouden en dezelfde cultuur; het is een sociaal construct dat gedurende de tijd verandert. Deze verschillen beïnvloeden de verwachtingen en ervaringen voor beide seksen binnen de samenleving en daarmee ook hun verantwoordelijkheden, rollen, taken en hun levenspatroon

Binnen het gender discours zijn er meerdere relevante concepten. Deze concepten zoals gender relaties, gender verschillen, gender rollen en gender behoeften hangen sterk met elkaar samen en vormen samen de basis voor verklaringen over hoe sociale relaties en verwachtingen het leven van man en vrouw beïnvloeden. Door deze concepten en de verschillende dimensies waarop zij het sociale leven beïnvloeden nader te onderzoeken, helpt om te verklaren waarom man en vrouw de leefomgeving anders gebruiken (Bowlby et al. 1986), zowel binnenshuis als buitenshuis in de bebouwde omgeving (Matrix, 1984).

\section{Samenleving en stedelijk ontwerp}

Een nadere beschouwing van de essentie van stedelijk ontwerp helpt met het ontrafelen van de nauwe relatie tussen de fysieke, zichtbare kwaliteit van openbare ruimte met het type sociale relaties en menselijke activiteiten die plaatsvinden op deze plekken. Carmona (2003), Greed (1998) en Moughtin (1992) zien stedelijk ontwerp als de kunst van het verbeteren van plekken voor mensen - het proces dat zich bezighoudt met de fysiekruimtelijke vorming van steden, om een stedelijke omgeving te creëren die voldoet aan de behoeften en ambities van de samenleving. Stedelijk ontwerp is veel meer dan 'grote architectuur' en meer dan een link leggen tussen deze architectuur en de stedelijke planning die daaraan vooraf ging. Het is betrokken zijn bij het volledige ruimtelijke complex in het planningsveld en bij kwaliteit van het publieke domein in alle dimensies.

In dit opzicht, valt stedelijk ontwerp grofweg uiteen in twee domeinen. Het eerste houdt zich bezig met (distributie van/uitstrooiing van) gebouwen en de plekken daartussen - voor functionele en visuele kwaliteit. Het tweede domein houdt zich bezig met het creëren van verschillende sociale activiteiten en verschillende sociale kansen op deze plekken. Dit tweede domein kan gezien worden als de sociale dimensie van het stedelijk ontwerpen en hoe meer mensen de ruimte gebruiken, hoe succesvoller het ontwerp van de plek is.

De sociale dimensie van stedelijk ontwerp kan ook gezien worden in de vijf basisdimensies die Kevin Lynch in zijn boek Good City Form benoemt: vitaliteit, gevoel, controle, geschiktheid en toegankelijkheid (vitality, sense, control, fit, and access). Deze basisdimensies zijn 


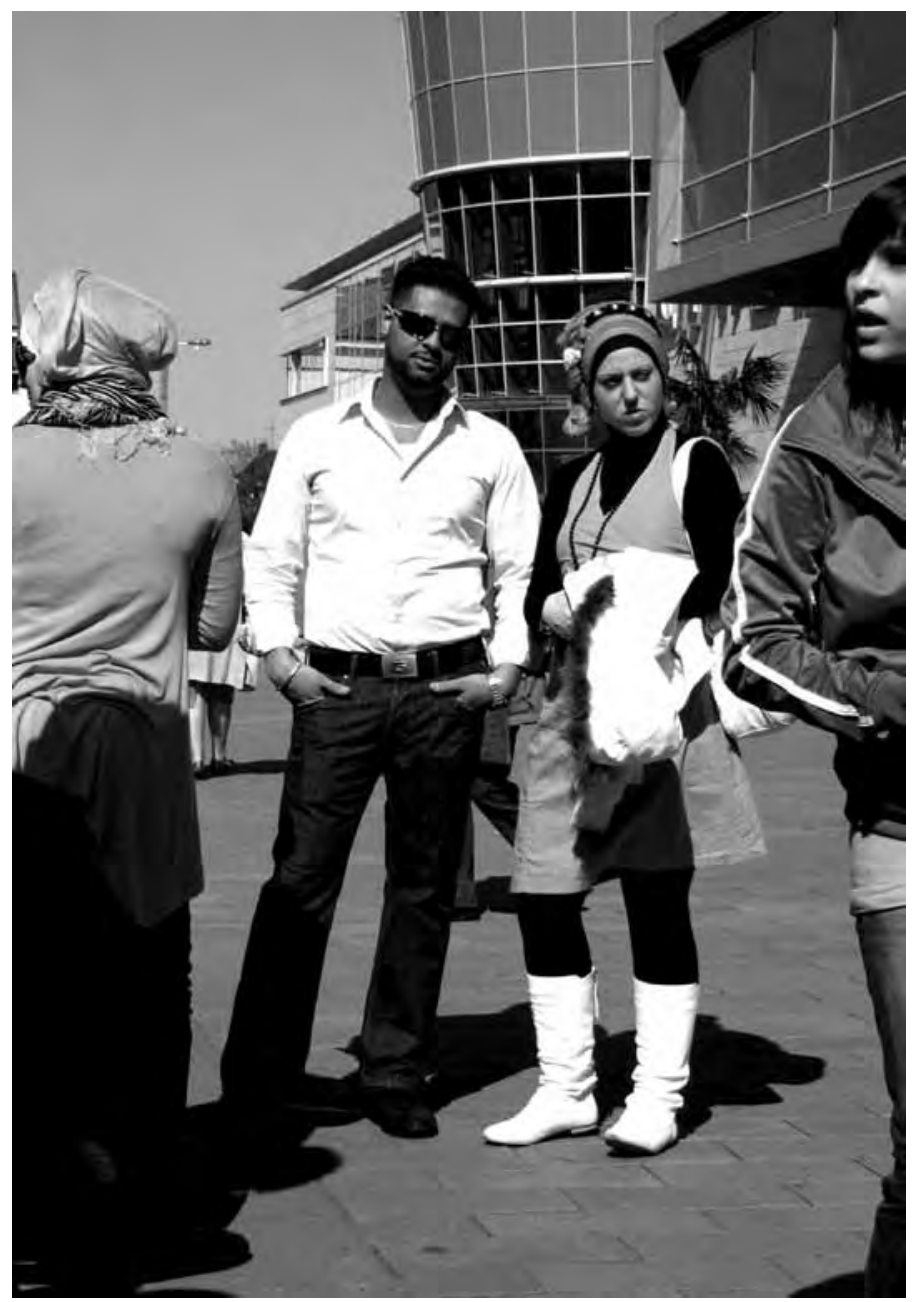

allemaal nodig voor het succes van een publieke ruimte. Al deze dimensies zijn gerelateerd aan behoeftes en ambities van de samenleving.

In de loop der tijd, is 'ruimte' geconceptualiseerd in twee hoofdstromingen: essentialistische conceptualisatie -de ruimte als een container, onafhankelijk van de objecten (mensen in de ruimte); en non-essentialistische conceptualisatie -de ruimte bestaat door de interrelaties van objecten (sociale relaties). Het eerste concept gaat uit van de onafhankelijke causale macht van de ruimte, terwijl het tweede concept ruimte ziet als een sociaal construct dat een werkelijk effect heeft op het dagelijks leven van mensen.

\section{Ervaren vrouwen de stad echt op een andere manier dan mannen?}

Velen geloven (net als Dear en Wolch, 1989) dat de stedelijke omgeving van grote invloed is op de activiteiten patronen van mensen en hun sociale leven in die ruimte. Jan Gehl (1996) verklaart hoe het ontwerp van de stedelijke omgeving gedrag beinvloedt. Hij beargumenteert dat het ontwerp van een plek invloed heeft op het aantal mensen dat die plek gebruikt en op het soort en de duur van activiteiten die men daar beoefent.

Ford (2000) stelt dat schrijvers zoals Jane Jacobs en William H. Whyte geloven dat: "Goede straten, trottoirs, parken en andere openbare ruimtes het beste in de menselijke natuur naar boven brengen en voorzien in de fundamenten voor een geciviliseerde en beschaafde/ fatsoenlijke samenleving. Alles komt goed als we het ontwerp maar goed krijgen."

Lawson (2001) stelt dat mensen die collectief leven op een bepaalde plek, geneigd zijn om regels te definiëren ten aanzien van het gebruik van die plek. Deze regels geven zowel de cultuur en tradities als de behoeftes van die samenleving weer. Lawson verheldert dit punt door te suggereren dat het vormen van een rij een bewijs is van conventioneel gedrag dat zijn oorsprong vindt in verschillende signalen in de ontworpen omgeving. Als er bijvoorbeeld touwen worden gebruikt als begrenzing in een bepaalde publieke ruimte geeft dat het signaal dat de gebruikers van die ruimte zich op een bepaalde manier moeten gedragen (ze moeten in de rij staan) om te bereiken wat ze willen (naar het theater).

In dit opzicht zijn de bebouwde omgeving en de gebruikers ervan meer dan alleen met elkaar verbonden: ze zijn van invloed op elkaar en worden beïnvloed door elkaar. Mensen formaliseren ruimte in lijn met hun cultuur, waarden, behoeftes en ambities. Tegelijkertijd beïnvloed de ruimtelijke organisatie hun gedrag.

\section{Gender en stedelijk ontwerp}

Stedelijk ontwerp gaat met name over het creëren van betere plekken voor mensen - het vestigen/leggen van een wederzijdse relatie tussen de ruimte en de gebruiker (de samenleving). Vanuit gender perspectief wordt de samenleving onderverdeeld in twee hoofdcategorieën: mannen en vrouwen. Ruimtelijk ontwerp is succesvol als het voldoet aan de behoeftes van de gehele samenleving. Aangezien vrouwen een groot aandeel hebben in de samenleving, leidt dit tot de vraag: voldoet de ruimtelijke omgeving aan de waarden en behoeftes van vrouwen? De relatie tussen gender en planning werd voor het eerst gelegd in de jaren '70. Gedurende de tweede feministische golf wordt er onderzoek gedaan naar vrouwen en de stedelijke omgeving. Sinds de jaren ' 80 is er een gender discours ontstaan binnen theorieën en debatten. De inzet van vrouwenbeweging leidde ertoe dat gender issues onderdeel werden van het planningsproces, op academisch en professioneel niveau. Veel thema's, zoals planning met en voor vrouwen, gender planning en vrouwelijke planningsbehoeften begonnen aandacht te krijgen.

Het is echter wel waard te melden, dat er al veel eerder zorgen van vrouwen over de stad en het stedelijke leven waren. Na de Amerikaanse Burgeroorlog en de wederopbouw hadden Amerikaanse vrouwen, die eeuwenlang leden onder sociale marginalisatie, het moeilijk de wereld te overtuigen dat ze meer waren dan huismussen wiens hoofdverantwoordelijkheid het dienen van huis en kinderen was. Als resultaat van deze inzet ontstond de 'Women's Club Movement' een van de eerste vrouwenbewegingen in Amerika, met als doel de vrouwelijke levenssfeer uit te breiden naar buitenshuis, in de samenleving.

De ideologie van 'municipal housekeeping' kwam rond dezelfde periode op en stoelde op de aanname dat het huis van een vrouw groter was dan vier muren, dat haar huis de stad was en dat het dus 


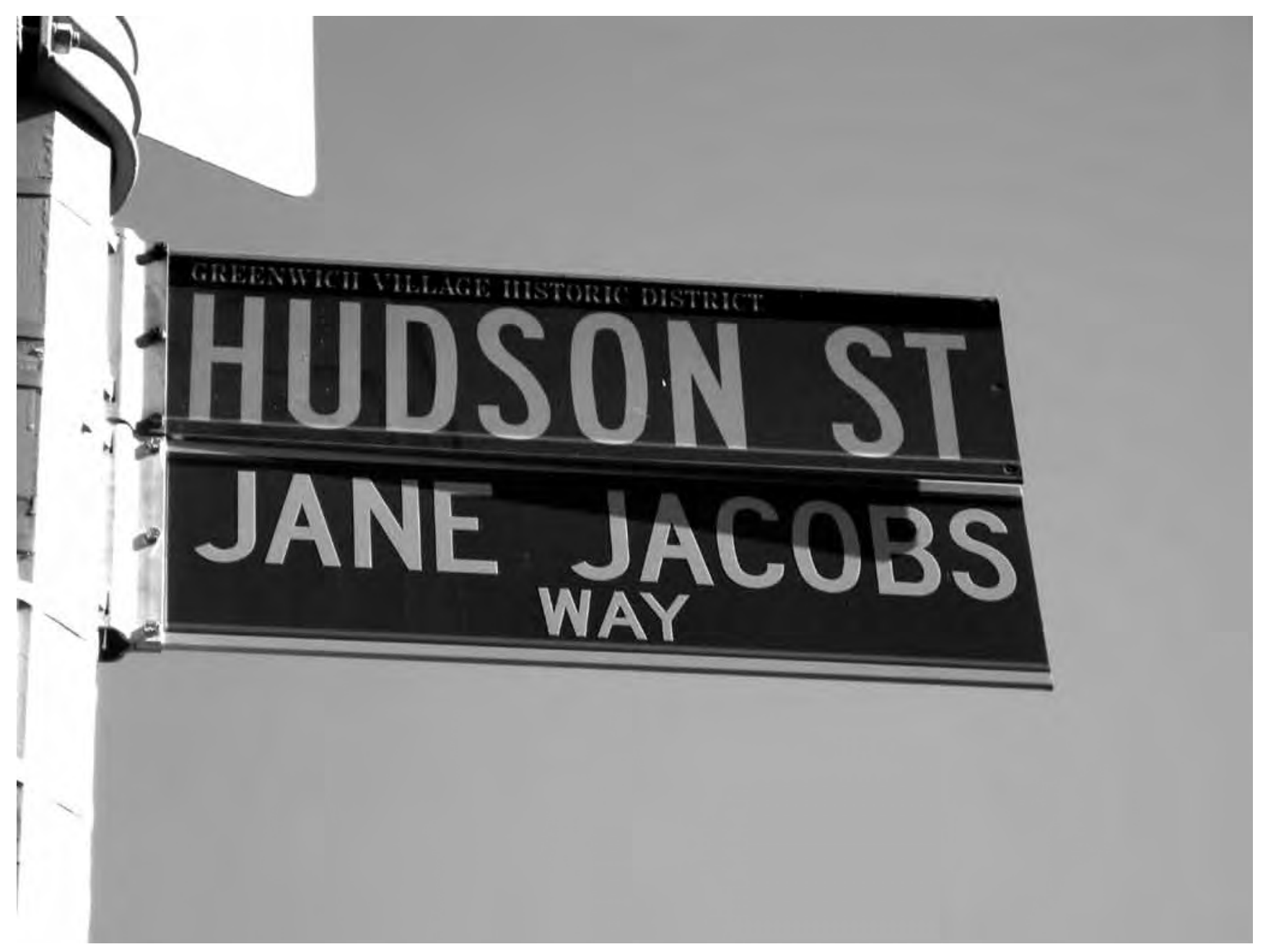

ook haar verantwoordelijkheid was de stad schoon en veilig te houden. Dit concept zorgde voor de bewustwording van de nieuwe rol van vrouwen in het openbare leven, de uitbreiding van hun verantwoordelijkheden naar de stad en het opvatten van de stad als een plek die ze kunnen vormen.

\section{Vrouwen ervaren de stad anders}

Als we de vraag "Voldoet de ruimtelijk omgeving aan de behoeftes en waarden van vrouwen?" willen beantwoorden, moeten we eerst onderzoeken of vrouwen inderdaad andere behoeftes en interesses heeft in de stedelijke omgeving, en of ze de stad op een andere manier ervaren dan mannen.

Feministische wetenschappers stoppen veel energie in het bewijzen dat de huidige stedelijke omgevingen niet geschikt zijn voor vrouwelijke ambities en waarden. Ze voorzien in een ruime voorraad aan interpretaties die deze claim ondersteunen. De basis van deze interpretaties is dat stedelijke planning altijd een mannenberoep is geweest en steden gevormd zijn door hun visie. Zoals Clara Greed en anderen stelden: vrouwen hebben een achterstandspositie in de stad omdat mannelijke planners stedelijke oplossingen hebben bedacht vanuit hun eigen perceptie van 'logisch' en 'normaal'. Zij hebben dus gepland voor de behoeftes van 'mensen zoals zij'.

Daarnaast werden vrouwen niet genoemd in de verhalen over de (planning) geschiedenis. Volgens de feministische historici is er een in de geschiedschrijving een grote kloof, of zijn er ontbrekende stukken in de puzzel van de planning geschiedenis. Dit heeft te maken hebben met de vrouwen kwesties die nooit geadresseerd zijn. De geschiedschrijving vertelt meer het 'hem' (de his-story) dan het 'haar' verhaal (de her-story) en negeert het feit dat het bestuderen van vrouwelijke ervaringen in het verleden helpt om het verleden door vrouwenogen te zien.

\section{Mensen formaliseren ruimte in lijn met hun cultuur, waar- den, behoeftes en ambities. Tegelijkertijd beiinvloed de ruimtelijke organisatie hun gedrag.}

Het ruimtelijk model van de 20ste eeuw was ook niet handig. Met het onderscheid tussen de'mannelijke steden en vrouwelijke suburbs' (Saegert, 1980) bestendigde het de notie van gescheiden sferen waar de plek van de vrouw het huis was en de man gezien werd als de kostwinner die buitenshuis regeerde. Om de vrouwelijke participatie te vergroten in het publieke leven, vochten feministes voor de 'opstand van de publieke vrouw' en benadrukten ze de noodzaak van een serieuze verandering in het planningsbeleid en in de ruimtelijke 
structuren van de metropolen.

Een van de sterkste argumenten, in mijn optiek, is de veranderende rol van de vrouw in de samenleving. In de loop van de tijd zijn vrouwen zich meer en meer gaan bewegen van de huiselijke sfeer naar de publieke sfeer. Ze zijn de stad en de stedelijke omgeving meer en op een andere manier dan voorheen gaan gebruiken. Er komen continu nieuwe manieren van het gebruik van openbare ruimte door vrouwen bij. De levenspatronen van vrouwen zijn hoe dan ook van invloed op hun behoeften en interesses in de stedelijke omgeving. Zo vertrouwen vrouwen in het algemeen bijvoorbeeld meer op openbaar vervoer dan mannen, wat leidt tot een verhoogde waarde van het openbaar vervoer voor hen.

Veel vrouwen die meerdere rollen vervullen (moeder, werknemer, kostwinner) ondervinden beperkingen in tijd en ruimte om al deze rollen te vervullen. Ze proberen daarom hun leven strategisch in te richten om deze beperkingen te overwinnen door bijvoorbeeld hun keuzes over werk, dagopvang en woonruimte samenhangend te maken. Bijvoorbeeld: een werkende moeder die geen auto tot haar beschikking heeft, probeert haar werk en dagopvang in de buurt van de busroute te regelen om haar toegang tot het openbaar vervoer te vergemakkelijken. Feministische wetenschappers brachten ook een andere interessante notie onder de aandacht voor wat betreft het vrouwelijke perspectief op stedelijkheid, te weten: "vrouwen delen wel dezelfde ruimte, maar niet dezelfde ervaring". Er is een grote diversiteit tussen vrouwen, bepaald door verschillende factoren zoals leeftijd, klasse, geloof, cultuur en etniciteit. Daarom is het van belang de samenhang tussen de natuur van en de relatie met deze factoren te begrijpen en de manier waarop deze het leven van vrouwen in steden beïnvloedt.

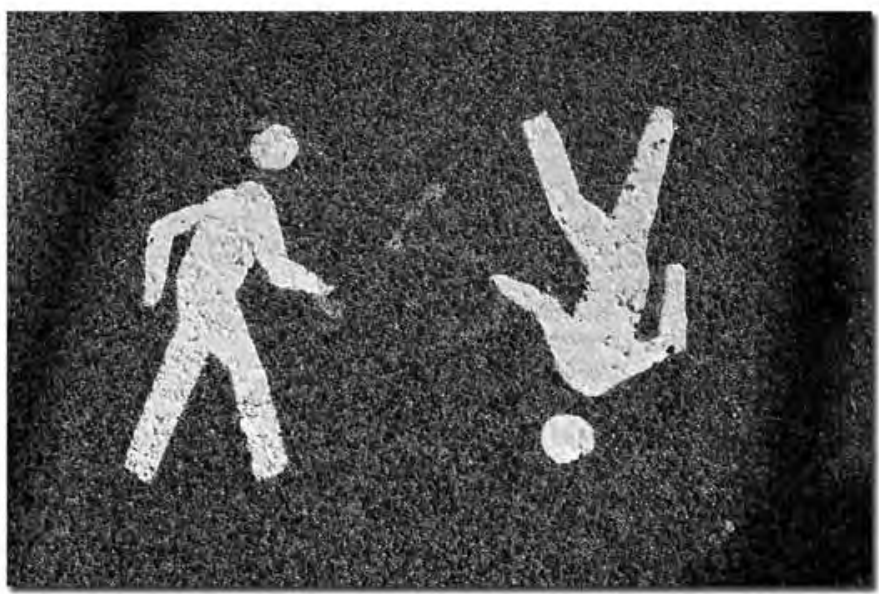

\section{Conclusie}

De feministische visie op de stedelijke omgeving helpt bij het bereiken van een versterkt gevoel voor de soort stedelijke plekken die passen bij het leven van vrouwen. Een van de benaderingen die hierbij helpt is om de sociale aspecten en de ruimtelijke aspecten van de stad die verbonden zijn met het leven van vrouwen te analyseren. Om te kunnen begrijpen hoe een bepaalde groep vrouwen de stad gebruikt, moeten we de aspecten die van invloed zijn op hun sociale en ruimtelijke leven onderzoeken, zoals sociale verwachtingen en gender relaties enerzijds en het huidige stedelijk beleid en de organisatie van ruimte anderzijds.
Ten slotte is dit misschien het momen om onze manier van denken te veranderen en moeten we beter ons best doen om de gender visie volwaardig onderdeel te laten zijn in in het planningsbeleid. Mannen en vrouwen gebruiken de stad beide en ze hebben beide het recht om zich comfortabel en tevreden te voelen in hun eigen stad.

\section{Mukarram Abbas (mabbas@vub.ac.be) is architecte en promo- vendus bij de Vrije Universiteit Brussel, Centre for Urban Research COSMOPOLIS - City, Culture \& Society,.}

\section{Literatuurselectie}

Carmona, M. et.al. (2003) Public Places- Urban Spaces. Great Britain: Architectural Press

Greed C. (2006) 'Making the divided city whole: mainstreaming gender into planning in the united kingdom' In: tijdschrift voor Economische en Sociale Geografie, Vo. 97, No. 3, July 2006, pp. 267-280(14). Blackwell Publishing Greed, C., Roberts, M. (1998) Introducing Urban Design, Interventions \&

Responses. Singapore: Longman

Norlander, K. (2003) Some Reflections on Gender Relations, Gender and power in the new Europe the 5th European Feminist Research conference. August 20-24, 2003 Lund University, Sweden

Kristine B. et.al. (2000) Gendering the city, U.S.: Rowman \& Littlefield Publishers, Inc

Matrix (1984) Making Space: Women and the Man-made Environment. London: Pluto

Moser, C. (1993) Gender Planning \& Development. USA \& Canada: Routledge. Moughtin, C. (1992) Urban Design: Street \& Square. Great Britain: Butterworth Architecture.

OECD Conference (1995) Women in the City: Housing, Services \& Urban Environment, OECD

Polity Press (1994) The Polity Reader in Gender Studies, Polity Press 